\title{
Meningitis por Salmonella Enteritidis en un lactante. Comunicación de un caso y revisión de la literatura
}

\author{
Salmonella Enteritidis meningitis in an infant. Case report and literature review
}

\author{
Constanza Bay ', Macarena Jofré', Daniela Kuzmanic', Constanza Aguirre ${ }^{3}$ y Valentina Gutiérrez ${ }^{4}$
}

'Programa de Formación en Pediatría, Departamento de Pediatría, Pontificia Universidad Católica de Chile. Santiago, Chile.
Escuela de Medicina, Pontificia Universidad Católica de Chile. Santiago, Chile.
${ }^{3}$ Servicio de Pediatría, Hospital Sótero del Río. Santiago, Chile.
${ }^{4}$ Unidad de Infectología Pediátrica, Hospital Sótero del Río. Santiago, Chile.

No hay conflictos de interés que declarar.

Sin fuentes de financiamiento.

Recibido: 26 de marzo de 2020 / Aceptado: 24 de julio de 2020

\section{Resumen}

La meningitis por Salmonella spp. es infrecuente en pediatría, pero debe sospecharse especialmente en menores de seis meses. Salmonella subespecie enterica es la más frecuente a nivel mundial, siendo el serovar Enteritidis el más importante. Tiene una alta tasa de complicaciones, predominando las colecciones y abscesos, por lo que se recomienda realizar una neuroimagen a todos los pacientes. A pesar que el manejo no está estandarizado, hay consenso en que el tratamiento de elección son las cefalosporinas de tercera generación. La resistencia antimicrobiana es infrecuente pero va en aumento, principalmente en países subdesarrollados. Presentamos el primer caso publicado en Chile de una meningitis por $S$. Enteritidis en un lactante de 11 meses, que se presentó con fiebre y una convulsión focalizada, con hemocultivos y cultivo de líquido cefalorraquídeo positivos. El paciente completó tratamiento con ceftriaxona y ciprofloxacina por cuatro semanas con buena respuesta.

Palabras clave: Salmonella Enteritidis; Salmonella no Typhi; meningitis.

\section{Introducción}

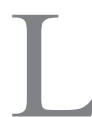

as infecciones por Salmonella no Typhi son frecuentes en pediatría, siendo una de las principales causas de infecciones transmitidas por alimentos, produciendo cuadros gastrointestinales, en su mayoría autolimitados ${ }^{1}$. Se ha descrito que entre 1 y $5 \%$ de estos pacientes pueden desarrollar una bacteriemia ${ }^{2}$. El 3-8\% de las bacteriemias se complican con osteomielitis, endocarditis, artritis,

\begin{abstract}
Salmonella spp meningitis is rare in pediatrics. However, it should be especially suspected in children younger than 6 months. The enteric subspecies is the most frequent worldwide, with the Enteritidis serovar being the most important. The complication rate is high, with collections and abscesses predominating. For this reason, neuroimaging is currently recommended for all patients. Even though management is not standardized, there is consensus that first line treatment should be with third generation cephalosporins. Antibiotic resistance is infrequent but increasing, mainly in underdeveloped countries. We present the first case reported in Chile of meningitis by Salmonella Enteritidis in an 11-month-old infant presenting with fever and focused epileptic crisis. Blood culture and cerebrospinal fluid culture were positive. The patient completed four weeks of treatment with ceftriaxone and ciprofloxacin with a good response.

Keywords: Salmonella Enteritidis, non typhoidal Salmonella; meningitis.
\end{abstract} nervioso central (SNC) ${ }^{3,4}$. Se estima que entre 50 y $75 \%$ de las meningitis por Salmonella spp. ocurren en lactantes de un año de edad ${ }^{5}$. El riesgo de presentar una salmonelosis invasora es mayor en recién nacidos, pacientes inmunocomprometidos, con hemoglobinopatías y anemias hemolíticas ${ }^{1,6}$. Presentamos el primer caso publicado en Chile de una meningoencefalitis por Salmonella Enteritidis en un lactante

de 11 meses. 


\section{Caso clínico}

Lactante de 11 meses, con antecedentes de apneas por reflujo gastroesofágico y una ITU febril a los 8 meses. Inició un cuadro de rinofaringitis aguda que evolucionó con compromiso del estado general, y posteriormente se agregó fiebre hasta $40^{\circ} \mathrm{C}$, irritabilidad y dos episodios de diarrea sin elementos patológicos. A los tres días presentó un episodio de desviación de la mirada hacia derecha, con movimientos tónico-clónicos del hemicuerpo derecho. Fue llevada a un consultorio ambulatorio de urgencia donde se administró diazepam y se derivó al servicio de urgencias de nuestro hospital. Ingresó febril, convulsionando, por lo que se administró lorazepam con lo que se logró yugular la crisis, tras un tiempo estimado de convulsión de 30 minutos. Se tomaron exámenes iniciales donde destacaba un hematocrito $33,8 \%$, leucocitos 29.550 céls/ $\mathrm{mm}^{3}$, segmentados $70 \%$, plaquetas $417.000 / \mathrm{mm}^{3}$, proteína $\mathrm{C}$ reactiva (PCR) $223 \mathrm{mg} / \mathrm{L}$ (valor normal $<5,0 \mathrm{mg} / \mathrm{L}$ ), pH 7,1; exceso base -7.8 , sedimento de orina normal. Se realizó una punción lumbar que dio salida a un líquido cefalorraquídeo (LCR) claro incoloro. El estudio citoquímico informó 58 céls $/ \mathrm{mm}^{3}, 56 \%$ polimorfonucleares, glucosa $71 \mathrm{mg} / \mathrm{dl}$, proteínas $0,22 \mathrm{~g} / \mathrm{L}$ y en la tinción de Gram no se observaron bacterias. Se tomaron muestras para hemocultivos, urocultivo y LCR. Se realizó una tomografía computada (TC) de cerebro que se informó normal.

Ingresó a la Unidad de Paciente Crítico (UPC) para su manejo. Inicialmente se administró una carga de fenitoína, seguido de una dosis de mantención, y posteriormente se reemplazó por levetiracetam. Por sospecha de una meningitis bacteriana aguda (MBA) se inició ceftriaxona y vancomicina en dosis meníngeas. Además se agregó aciclovir hasta descartar una encefalitis herpética. A las $12 \mathrm{~h}$ de incubación se informó un hemocultivo positivo para bacilos gramnegativos, el que posteriormente se identificó como Salmonella spp., por lo que al persistir febril se agregó ciprofloxacina i.v. $20 \mathrm{mg} / \mathrm{kg} /$ día. El antibiograma informó sensibilidad a ampicilina, cefotaxima, ciprofloxacina, cloranfenicol y cotrimoxazol. Al día siguiente se informó el cultivo de LCR con escasa cantidad de bacilos gramnegativos, identificados posteriormente como Salmonella spp., tras lo cual se suspendieron vancomicina y aciclovir. Se enviaron muestras al Instituto de Salud Pública (ISP), siendo tipificada como Salmonella Enteritidis. El antibiograma informó sensibilidad a ampicilina, cefotaxima, cotrimoxazol y cloranfenicol. Además, se rescata la susceptibilidad a ciprofloxacina no informada, sensible. Al tercer día, la paciente persiste febril, con ascenso de PCR hasta $310 \mathrm{mg} / \mathrm{L}$, leucocitos de 24.730 céls/ $\mathrm{mm}^{3}$ y una muestra de orina no inflamatoria. Tras $72 \mathrm{~h}$ de antibacterianos se repitieron los hemocultivos y el estudio de LCR, y se aumentó la dosis de ciprofloxacina i.v. a 30 $\mathrm{mg} / \mathrm{kg} /$ día, con el fin de optimizar su llegada al SNC. El estudio del LCR informó un aspecto claro, incoloro, con 90 céls $/ \mathrm{mm}^{3}, 46 \%$ polimorfonucleares, proteínas $0,48 \mathrm{~g} / \mathrm{L}$, glucosa $57 \mathrm{mg} / \mathrm{dl}$ y sin bacterias al Gram. El resultado de los hemocultivos y cultivo de LCR de control fueron negativos. Se realizó una resonancia magnética (RM) cerebral que fue informada sin hallazgos patológicos. Las pruebas hepáticas y ecografía abdominal también fueron normales. No presentó compromiso osteoarticular a la exploración clínica. Dado lo inusual de la etiología de la MBA, se decidió realizar estudio inmunológico con recuento de inmunoglobulinas, subpoblaciones linfocitarias y linfocitos $\mathrm{T}$ de memoria, estudio de linfoproliferación y estallido respiratorio los cuales fueron todos normales. También se descartó una infección por VIH.

Se indagaron antecedentes epidemiológicos, destacándose un probable consumo de huevo crudo, sin contactos con enfermos o sospechosos.

Se completaron 28 días de antimicrobianos intravenosos. Evolucionó bien, afebril, con normalización de los parámetros inflamatorios, sin nuevas crisis convulsivas y con un examen neurológico normal. Para completar el estudio inmunológico se solicitó un panel genético de inmunodeficiencias, pendiente hasta la fecha. Actualmente se mantiene en buenas condiciones a seis meses de seguimiento ambulatorio multidisciplinario, con desarrollo neurológico y psicomotor adecuados, y examen de audición y oftalmológico normales.

\section{Discusión}

La meningitis por Salmonella spp. es infrecuente en niños sanos. Sin embargo, se debe sospechar en pacientes pediátricos con riesgo de infecciones bacterianas diseminadas. De presentarse, se describen clásicamente casos de esta zoonosis cuyo mecanismo de entrada más frecuente es el tracto gastrointestinal ${ }^{7}$. Por esto, es importante mantener la vigilancia epidemiológica para promover la sospecha, lograr un diagnóstico precoz y tratamiento oportuno y de esta manera, disminuir las complicaciones asociadas a las infecciones por Salmonella.

El género Salmonella pertenece a la familia Enterobacteriaceae. Son bacterias gramnegativas no esporuladas $\mathrm{y}$ anaerobias facultativas ${ }^{8}$. El género está constituido por dos especies, S. enterica y S. bongori. Mediante la serotipificación de Kauffmann-White ${ }^{9}$ que consiste en la caracterización, por aglutinación de los antígenos somáticos $\mathrm{O}$, de los antígenos flagelares $\mathrm{H}$ y del antígeno capsular Vi, se han descrito más de 2600 serovares $^{* 10}$. Las serovariedades zoonóticas se describen como Salmonella no Typhi, las que se encuentran ampliamente distribuidas en el reino animal, siendo las aves y sus derivados las

\footnotetext{
* Nota del ed.: serovar es sinónimo de serotipo. El Laboratorio de Referencia (ISP) ha adoptado esta nomenclatura.
} 
fuentes más comunes de infección. Generalmente, se asocia a brotes de enfermedades transmitidas por alimentos, manifestándose por un cuadro de gastroenteritis aguda ${ }^{7}$. Se estima que cada año hay 94 millones de casos de gastroenteritis por Salmonella no Typhi en el mundo, con 155.000 muertes $^{11}$. En un estudio realizado en E. U. A. en niños bajo 5 años de edad con enfermedad entérica bacteriana confirmada, se informó a Salmonella no Typhi como el patógeno más comúnmente aislado (42\%) seguido por Campylobacter spp. (28\%), Escherichia coli 0157, Shigella spp. y Yersinia enterocolitica ${ }^{12}$. Da Silva Mello de Martinez publicó un estudio transversal de diarreas en un centro de Paraguay. Se incluyeron 167 casos pediátricos, dentro de los cuales se identificó Salmonella spp. en $7 \%$ de los aislados, Shigella spp. en $8 \%$ y Campylobacter spp. en un $4 \%{ }^{13}$. Otro estudio descriptivo en un centro de referencia pediátrico de Uruguay incluyó 46 pacientes con Salmonella spp aislada. De las muestras estudiadas, ocho casos eran de deposiciones, 15 de hemocultivos, dos de punciones osteo-articulares y una de un absceso de extremidad inferior. No se describieron casos de compromiso del SNC. Los serovares más frecuentemente aislados fueron: Typhimurium $26(56 \%)$ y Enteritidis $14(30 \%)^{14}$.

Las zoonosis son enfermedades transmitidas de animales a humanos, que representan una gran amenaza para la salud. La infección por Salmonella spp. puede ser el resultado del contacto directo con animales infectados $\mathrm{o}$ indirectos por contacto con su ambiente. Clásicamente se describen en animales de ganado, aves de corral y cerdos. Sin embargo, también se encuentran en animales salvajes, anfibios, peces y roedores. En Chile, en relación a la fauna silvestre, diversos reportes sugieren que la infección es prevalente en animales de ambientes acuáticos, incluyendo aves y mamíferos, siendo en su mayoría cuadros asintomáticos. Los serovares más frecuentemente aislados en estos casos son $S$. Enteritidis y $S$. Typhimurium. No existen antecedentes respecto de la presencia de Salmonella spp. en mascotas en Chile; sin embargo, el alto número de animales vagabundos lo transforma en un factor de riesgo a considerar ${ }^{15}$. Estudios en países desarrollados describen una prevalencia de infección entre 1 y $5 \%$ de los animales estudiados ${ }^{16,17}$. Especial atención debe ponerse frente a la tenencia de mascotas exóticas, lo cual se ha transformado en una tendencia creciente en los últimos años. Aves psitácidas, anfibios, reptiles y roedores se encuentran entre los tipos de animales que frecuentemente se asocian a casos clínicos en sus dueños. Un estudio nacional retrospectivo realizado por profesionales del Servicio Agrícola y Ganadero (SAG) en reptiles importados y mantenidos en cuarentena entre los años 1997 y 2008 , determinó que $70 \%$ de ellos era portador de Salmonella spp. ${ }^{18}$. Otro estudio chileno reportó salmonelosis en lactantes como consecuencia de la crianza de tortugas de agua adquiridas en ferias libres ${ }^{19}$.
Tanto la manipulación directa de los animales, como la contaminación cruzada de sus alimentos son las causas más probables de la transmisión. Por este motivo se debe educar acerca del riesgo que significa la tenencia de este tipo de animales en forma doméstica. Es muy relevante la búsqueda activa de estos factores de riesgo a la hora de investigar la fuente de adquisición de la bacteria. Aún así, lo más frecuente en nuestro medio sigue siendo el contacto con aves, huevos y el consumo de alimentos que no cumplen con la cadena de procesamiento adecuada o con las medidas de higiene rigurosas en su preparación ${ }^{20}$.

Se ha descrito que en países de altos ingresos, la infección gastrointestinal se asocia a una bacteriemia secundaria hasta en $5 \%$ de los pacientes inmunocompetentes, con una mortalidad atribuible de 1 a $5 \%{ }^{2}$. En niños, la infección supurativa focal asociada a bacteremia por Salmonella no Typhi es menos común que en adultos ${ }^{21}$. Un 3-8\% de los pacientes con bacteriemia se complica con un cuadro de osteomielitis, endocarditis, artritis, neumonía, ITU o meningitis ${ }^{3,4}$. Además, Salmonella no Typhi tiene la capacidad de permanecer dentro de los macrófagos del sistema reticuloendotelial durante largos períodos de tiempo, siendo capaz de invadir a través del sistema circulatorio ante un compromiso del sistema inmunológico ${ }^{22}$.

El primer caso de meningitis por Salmonella spp. fue descrito en 1907 por Ghon y cols. ${ }^{23}$. Desde entonces, se han publicado casos aislados o series pequeñas, lo cual refleja lo infrecuente de esta patología. La mayoría de los casos de salmonelosis publicados en la literatura científica pertenecen a países en vías de desarrollo. La incidencia reportada va desde $0,1 \%$ en Gran Bretaña, hasta $12 \%$ en Malawi ${ }^{24}$. Es probable que se deba a que estos países son zonas endémicas de infección por VIH, parasitosis y anemia de células falciformes, los cuales son probables factores de riesgo para desarrollar complicaciones ${ }^{25-27}$. En Chile, la última tasa de incidencia de infecciones por Salmonella spp. reportada por el ISP fue de 10,3 por 100.000 habitantes el 2018, concentrándose los casos en el grupo etario entre 0 y 4 años con $22 \%$, seguido del grupo entre 5 y 9 años con $13,7 \%$. En este boletín de vigilancia 2014-2018 se informó que 11,5\% eran muestras de origen extraintestinal ${ }^{7,28}$. En la última década, en Chile ha habido una fuerte alza en el número de inmigrantes sudamericanos, con un cambio en la distribución de los países de origen. Debe ponerse especial atención en aquellos provenientes de países con alta prevalencia de hemoglobinopatías, como por ejemplo, Haití.

Salmonella spp. es identificada en menos de $1 \%$ de los casos de MBA en lactantes y recién nacidos ${ }^{29}$. Algunos de los serovares más frecuentemente asociados a infección del SNC son $S$. Typhimurium (75-88\%), seguido de $S$. Enteritidis (8-16\%) y con menos frecuencia $S$. Typhi $(1-4 \%)^{24}$. En Chile, se mantiene una vigilancia 
epidemiológica de laboratorios en relación a diversos microorganismos de relevancia para la salud pública. En el último boletín de Salmonella spp. del ISP, que considera el período 2014-2018, se reportó una mayor prevalencia de la cepa $S$. Enteritidis (60,3\%), seguida de $S$. Typhimurium $(12,9 \%), S$. Infantis $(4,1 \%)$ y finalmente $S$. Typhi $(2 \%)$ y $S$. Paratyphi $B(2 \%)$. El 88,5\% de las cepas de este período provino de muestras de origen intestinal ${ }^{7}$. Además, dentro de los brotes de enfermedades transmitidas por alimentos, de notificación obligatoria en Chile, entre 2013 y 2017, Salmonella spp. fue el principal agente $(36 \%)^{30}$. Un estudio post mortem publicado en México, que incluyó 80 niños con infección demostrada por Salmonella spp., reportó 41 casos por $S$. grupo B y 14 casos por $S$. Typhi. Dentro de las manifestaciones clínicas se describieron ocho casos de meningitis purulenta ${ }^{31}$.

Respecto al manejo inicial de una infección del SNC, es importante determinar si hay sospecha de compromiso meningeo y/o encefálico. En el caso presentado se inició tratamiento antimicrobiano por sospecha de MBA, incluyendo aciclovir hasta descartar una encefalitis herpética. Actualmente, el tratamiento de la meningitis por Salmonella spp. es aún un desafío dado que no se encuentra estandarizado. Tradicionalmente se ha asociado con una elevada morbimortalidad y un alto porcentaje de recaídas. En 2003, Owusu-Ofori y cols. describieron una pobre respuesta de la salmonelosis meníngea al tratamiento con ampicilina y cloranfenicol, y regular a cotrimoxazol. Sin embargo, el pequeño número de casos no permite hacer una recomendación ${ }^{32}$. Este pronóstico desfavorable probablemente está dado porque Salmonella spp. es una bacteria intracelular facultativa, por lo que requiere antibacterianos con acción bactericida y con buena penetración a través de la barrera hematoencefálica. La utilización de cefalosporinas de tercera generación ha emergido como tratamiento de elección, mejorando significativamente el pronóstico de la enfermedad. La Academia Americana de Pediatría recomienda el tratamiento de la meningitis por Salmonella spp. con cefotaxima o ceftriaxona por un mínimo de cuatro semanas ${ }^{1,33}$. Sin embargo, se han reportado casos de recaída con cefalosporinas ${ }^{34}$. Como en toda meningitis por bacilos gramnegativos, se recomienda repetir el estudio del LCR a las $48 \mathrm{~h}$ para asegurar su esterilidad. En relación a los casos en que el LCR persiste positivo, ha surgido como una alternativa las fluoroquinolonas ${ }^{1}$, mostrando tasas de cura de hasta $88,9 \%{ }^{32}$. Esta familia de antibacterianos presenta una mayor actividad intracelular y liposolubilidad. Al igual que cotrimoxazol, su lipofilicidad favorece su penetración en el SNC. Según la relación entre el área bajo la curva en LCR y suero (AUCCSF/ AUCS), muestran una penetración en el LCR, tanto en ausencia como en presencia de inflamación meníngea, mayor que los $\beta$-lactámicos y aminoglucósidos ${ }^{35,36}$. Por ende, tanto las fluoroquinolonas como cotrimoxazol son alternativas de segunda línea frente a meningitis refractarias o con sospecha de complicación, siendo importante guiarse por los patrones de resistencia locales. Por otra parte, representan una buena alternativa de vía oral para completar el tratamiento de forma ambulatoria en cuadros de infecciones no meníngeas.

A pesar que en Sudamérica se han reportado cepas de Salmonella con resistencia intermedia a ciprofloxacina, la prevalencia de cepas completamente resistentes sigue siendo predominante en países en vías de desarrollo ${ }^{(2)}$. La vigilancia epidemiológica en Chile reporta un amplia sensibilidad a los antimicrobianos de uso clínico. Entre los años 2014 y 2018, Salmonella spp. presentó una resistencia a cefotaxima entre 2 y $7 \%$ en las cepas de origen intestinal y entre 1 y $9 \%$ en las de origen extraintestinal. Para ciprofloxacina se reporta una resistencia de 0 a $1 \%$ e intermedia entre 11 y $15 \%$ en cepas intestinales, con 0 a $2 \%$ de resistencia y 14 a $19 \%$ de resistencia intermedia en cepas extraintestinales. Particularmente en 2018, las cepas de $S$. Enteritidis de origen extraintestinal no describen resistencia a los antimicrobianos testeados, y las cepas intestinales solo describen $1 \%$ de resistencia a ampicilina y cloranfenicol, y 3\% de resistencia intermedia a ciprofloxacina. Respecto a otros serovares, se describe una resistencia intermedia a ciprofloxacina de $S$. Typhimurium, $S$. Typhi y $S$. Paratyphi B en 3\%, 4,3\% y 41,6\%, respectivamente. Salmonella Infantis es el serotipo con mayor resistencia, con $88 \%$ a ampicilina y cefotaxima, $16,6 \%$ a ciprofloxacina, $83 \%$ a cloranfenicol y $55,5 \%$ a cotrimoxazol. Los mecanismos de resistencia identificados fueron en $94 \% \beta$-lactamasas de espectro extendido y en $6 \% \beta$-lactamasas del tipo AmpC. En relación a los datos epidemiológicos en Chile, es relevante la identificación de los serovares para la elección de la terapia antimicrobiana, dada la resistencia sobre todo de los serovares $S$. Infantis y $S$. Paratyphi $\mathrm{B}^{7}$.

En los casos de meningitis por Salmonella spp. se recomienda un estudio con neuroimagen, aun cuando el paciente no tenga síntomas neurológicos y con una buena respuesta al tratamiento antibacteriano, dado el alto riesgo de recaídas y complicaciones ${ }^{32}$. Dentro de las complicaciones agudas que se han descrito, las más frecuentes son las convulsiones prolongadas, seguido de hidrocefalia, colecciones subdurales, empiema y abscesos intracraneales, infartos, ventriculitis, cerebritis, trombosis venosa y parálisis de nervios craneales ${ }^{37}$. Los hallazgos de RM descritos en la meningoencefalitis por Salmonella spp. incluyen edema vasogénico cerebral difuso, edema de esplenio y edema focal de sustancia blanca asociado con cerebritis $^{38,39}$. En el caso presentado la RM cerebral fue normal, lo cual permitió descartar este tipo de complicaciones intracraneales. A largo plazo se ha descrito trastornos del lenguaje, discapacidad motora, retraso mental, epilepsia, pérdida auditiva neurosensorial, déficit visual, parálisis del 
nervio abducente, microcefalia e hidrocefalia ${ }^{37}$. En nuestro caso, la paciente no desarrolló complicaciones intracraneales y continúa en controles periódicos, siendo hasta ahora su desarrollo neurológico normal. El pronóstico de la meningitis por Salmonella spp. es variable, con tasas de mortalidad que pueden llegar a 50-70\% ${ }^{37}$.

Realizamos una búsqueda bibliográfica de los casos publicados de meningitis por Salmonella spp. en niños (Tabla 1). La búsqueda se realizó en PubMed utilizando los términos "Salmonella"; "Meningitis, bacterial"; "Central nervous system infections" de forma pareada e independiente. También se utilizó la base de datos LILACS, Epistemonikos y Scielo, usando los términos "meningitis" y "Salmonella". Se incluyeron reportes de casos, series de casos y revisiones, considerando sólo los casos pediátricos y neonatales. No se logró tener acceso a seis estudios que registran publicación antes de 1992. Se encontraron casos reportados desde 1944, con cuatro casos de meningitis por $S$. Parathypi A y B. En total logramos obtener acceso a 107 casos pediátricos publicados. Más de la mitad de los reportes provienen de países en vías de desarrollo, siendo los principales Taiwán, Malasia, India, Vietnam y Pakistán. Más de la mitad de los niños fueron lactantes bajo tres meses de edad, siendo $87 \%$ menor o igual a 12 meses (Tabla 1).

\begin{tabular}{|c|c|}
\hline \multicolumn{2}{|l|}{ Edad } \\
\hline$\leq 3$ meses & 56 \\
\hline$\leq 12$ meses & 37 \\
\hline$\leq 16$ años & 6 \\
\hline N/D & 8 \\
\hline \multicolumn{2}{|l|}{ Factores de riesgo } \\
\hline Sin factor de riesgo & 37 \\
\hline Desnutrición & 7 \\
\hline Contacto con animales & 6 \\
\hline RNPT & 4 \\
\hline Viaje a Africa & 1 \\
\hline Ingesta de riesgo & 1 \\
\hline Otros & 4 \\
\hline $\mathrm{N} / \mathrm{D}$ & 49 \\
\hline Complicaciones & 76 \\
\hline Absceso/empiema/colección & 30 \\
\hline Hidrocefalia & 21 \\
\hline Convulsiones & 15 \\
\hline Ventriculitis & 7 \\
\hline Infartos cerebrales & 5 \\
\hline Recurrencia & 9 \\
\hline Secuelas neurológicas & 6 \\
\hline Fallece & 10 \\
\hline N/D & 6 \\
\hline
\end{tabular}

Sólo en 23 pacientes se informó algún factor de riesgo específicos que pudiese haber favorecido la infección, como la desnutrición y el contacto con algún animal de riesgo. La especie más frecuentemente identificada fue Salmonella Enteritidis, seguida de $S$. Typhimurium, $S$. Typhi y $S$. Parathypi B, pertenecientes todas a la especie enterica (Tabla 2). Casi todas son parte de la subespecie $S$. enterica (I), excepto un caso de $S$. Arizonae (IIIa) y uno de $S$. Houtanae (IV). El tratamiento antibacteriano no ha variado en los últimos años. La gran mayoría de los pacientes se trató con una cefalosporina de tercera ge-

\begin{tabular}{|c|c|}
\hline Serovars & Casos \\
\hline Salmonella spp. & 27 \\
\hline S. Enteritidis & 18 \\
\hline S. Typhimurium & 9 \\
\hline S. Typhi & 8 \\
\hline S. Paratyphi B & 5 \\
\hline S. Paratyphi A & 4 \\
\hline S. Infantis & 2 \\
\hline S. Panama & 3 \\
\hline S. Arizonae & 2 \\
\hline S. Heidelberg & 2 \\
\hline S. Newport & 2 \\
\hline S. Abony & 1 \\
\hline S. Agama & 1 \\
\hline S. Agona & 1 \\
\hline S. Berta & 1 \\
\hline S. Choleraesuis & 1 \\
\hline S. Claibornei & 1 \\
\hline S. Derby & 1 \\
\hline S. Enteritidis & 1 \\
\hline S. Hadar & 1 \\
\hline S. Houtenae & 1 \\
\hline S. Kingabwa & 1 \\
\hline S. Matopeni & 1 \\
\hline S. Montevideo & 1 \\
\hline S. no Typhi & 1 \\
\hline S. Oranienburg & 1 \\
\hline S. Oslo & 1 \\
\hline S. Pomona & 1 \\
\hline S. Poona & 1 \\
\hline S. Saintpaul & 1 \\
\hline S. Sandiego & 1 \\
\hline S. Stanley & 1 \\
\hline S. Uzaramo & 1 \\
\hline S. Virchow & 1 \\
\hline S. Vitkin & 1 \\
\hline S. Westerstede & 1 \\
\hline
\end{tabular}


neración, asociado o no principalmente a cloranfenicol o ciprofloxacina, y con menos frecuencia, cotrimoxazol. La duración de la terapia fue variable, con promedio de tres a cuatro semanas. De las cepas estudiadas con antibiograma, la resistencia a antimicrobianos fue infrecuente. Se describieron complicaciones en $70 \%$ de los pacientes (Tabla 1). Dentro de éstas, lo más frecuente fueron las lesiones infecciosas locales (abscesos, colecciones o empiema), seguido de hidrocefalia, convulsiones, ventriculitis e infartos cerebrales. Nueve pacientes evolucionaron con recurrencia de la meningitis y 10 pacientes fallecieron, describiendo una mortalidad de $9 \%$.

\section{Conclusiones}

La meningitis por Salmonella spp. es infrecuente en pediatría, pero debe sospecharse especialmente en lactantes bajo 12 meses de edad. Son zoonosis más prevalentes en los países en desarrollo; sin embargo, las fuentes de contagio se han diversificado con los años, por lo que se debe tener precaución en el contacto de niños con animales de riesgo. Las complicaciones agudas son frecuentes siendo recomendable realizar una neuroimagen a todos los pacientes. El seguimiento debe ser multidisciplinario dado las secuelas que se describen a largo plazo. Actualmente, el tratamiento de primera línea son las cefalosporinas de tercera generación, con una duración de cuatro semanas. Las fluoroquinolonas y cotrimoxazol son alternativas de segunda línea que han surgido en relación al alza en las tasas de resistencia descritas. En Chile, la resistencia a los antibacterianos de uso frecuente sigue siendo baja.

\section{Referencias bibliográficas}

1.- Wen S C, Best E, Nourse C. Non-typhoidal Salmonella infections in children: Review of literature and recommendations for management. J Paediatr Child Health 2017; 53: 936-41. doi: 10.1111/jpc.13585.

2.- Crump J A, Sjolund-Karlsson M, Gordon M A, Parry C M. Epidemiology, clinical presentation, laboratory diagnosis, antimicrobial resistance, and antimicrobial management of invasive Salmonella infections. Clin Microbiol Rev 2015; 28: 901-37. doi: 10.1128/CMR.00002-15.

3.- Shimoni Z, Pitlik S, Leibovici L, Samra Z, Konigsberger H, Drucker M, et al. Nontyphoid Salmonella bacteremia: age-related differences in clinical presentation, bacteriology, and outcome. Clin Infect Dis 1999; 28: 822-7. doi: $10.1086 / 515186$.

4.- Weinberger M, Andorn N, Agmon V, Cohen $\mathrm{D}$, Shohat T, Pitlik S. Blood invasiveness of Salmonella enterica as a function of age and serotype. Epidemiol Infect 2004; 132: 1023-8. doi: 10.1017/s0950268803001109.

5.- Christenson J C. Salmonella infections. Pediatr Rev 2013; 34: 375-83. doi: 10.1542/pir.34-9375

6.- Galanakis E, Bitsori M, Maraki S, Giannakopoulou C, Samonis G, Tselentis Y. Invasive non-typhoidal salmonellosis in immunocompetent infants and children. Int J Infect Dis 2007; 11: 36-9. doi: 10.1016/j. ijid.2005.09.004.

7.- Boletín de Vigilancia de Laboratorio. Salmonella spp. 2014-2018. Instituto de Salud Pública, Departamento de Epidemiología, Ministerio de Salud de Chile. Vol. 9. N 13 , Diciembre 2019. Disponible en: http://www. ispch.cl/sites/default/files/BoletínSalmonella12052020A.pdf.
8.- Ray B. Fundamental food microbiology. Boca Raton: CRC Press. Third Edition. 2004. Disponible en: http://nuristianah.lecture. ub.ac.id/files/2014/09/fundamental-foodmicrobiology.pdf

9.- Grimont P, Weill F X. Antigenic formulae of the Salmonella serovars. WHO Collaborating Centre for Reference and Research on Salmonella Paris: Pasteur Institute. $9^{\text {th }}$ edition 2007. Disponible en: https://www.pasteur.fr/ sites/default/files/veng_0.pdf.

10.- Echeita M A, Aladueña A M, Díez R, Arroyo M, Cerdán F, Gutiérrez R, et al. Distribución de los serotipos y fagotipos de Salmonella de origen humano aislados en España en 19972001. Enferm Infecc Microbiol Clin 2005; 23 : 127-34. doi: 10.1157/13072161.

11.- Majowicz S E, Musto J, Scallan E, Angulo F J, Kirk M, O’Brien SJ, et al. The global burden of nontyphoidal Salmonella gastroenteritis. Clin Infect Dis 2010; 50: 882-9. doi: 10.1086/650733.

12.- Scallan E, Mahon B E, Hoekstra R M, Griffin P M. Estimates of illnesses, hospitalizations and deaths caused by major bacterial enteric pathogens in young children in the United States. Pediatr Infect Dis J 2013; 32: 217-21. doi: 10.1097/ INF.0b013e31827ca763.

13.- Da Silva Mello de Martínez M E. Enfermedad diarreica aguda en niños. Agentes causales más comunes en una comunidad del Chaco Central. Pediatr (Asunción). 2011; 38 (3); 191-8.

14.- Barrios P, Badía F, Misa V, Mota M I, Martínez A, Mariño H, et al. Un quinquenio de experiencia (2005-2010) con infecciones por Salmonella spp en un centro nacional de referencia en pediatría. Rev Chilena Infectol 2017; 34: 359-64. doi: 10.4067/s071610182017000400359 .
15.- Barreto M, Castillo-Ruiz M, Retamal P. Salmonella enterica: una revisión de la trilogía agente, hospedero y ambiente, y su trascendencia en Chile. Rev Chilena Infectol 2016; 33: 547-57. doi: 10.4067/S071610182016000500010.

16.- Procter T D, Pearl D L, Finley R L, Leonard E K, Janecko N, Reid-Smith R J, et al. A cross-sectional study examining Campylobacter and other zoonotic enteric pathogens in dogs that frequent dog parks in three cities in southwestern Ontario and risk factors for shedding of Campylobacter spp. Zoonoses Public Health 2014; 61: 208-18. doi: 10.1111/zph.12062.

17.- Chomel B B. Emerging and re-emerging zoonoses of dogs and cats. Animals (Basel) 2014; 4: 434-45. doi: 10.3390/ani4030434.

18.- Osorio M, Saldías M, Valiente K. Estudio retrospectivo de presencia de Salmonella spp. en reptiles ingresados a Chile a través de la Estación Cuarentenaria Pecuaria, 1997-2008. Boletín Veterinario Oficial 2010; 12: 1-10. Disponible en: https:// www2.sag.gob.cl/Pecuaria/bvo/BVO_12_ II_semestre_2010/PDF_articulos/estudio_ salmonella_lab.pdf.

19.- Braun S, Spalloni W, Ferreccio F, Postigo J, Fernández A, Porte L, et al. Gastroenteritis por Salmonella spp. en tres lactantes asociada a contacto con tortugas acuáticas. Rev Chilena Infectol 2015; 32: 334-8. doi: 10.4067/S071610182015000400013.

20.- Chlebicz A, Slizewska K. Campylobacteriosis, salmonellosis, yersiniosis, and listeriosis as zoonotic foodborne diseases: A review. Int J Environ Res Public Health 2018; 15: 863. doi: 10.3390/ijerph15050863.

21.- Bar-Meir M, Raveh D, Yinnon A M, 
Benenson S, Rudensky B, Schlesinger Y. Non-Typhi Salmonella gastroenteritis in children presenting to the emergency department: characteristics of patients with associated bacteraemia. Clin Microbiol Infect 2005; 11: 651-5. doi: 10.1111/j.14690691.2005.01200.x.

22.- Rodríguez C H, de Mier C, Bogdanowicz E, Caffer M I, Garcia S, Lasala M B, et al. Salmonelosis extraintestinal: clínica, epidemiología y resistencia antimicrobiana. Acta Bioquímica Clínica Latinoam 2007; 41: 379-83. Disponible en: https://www.redalyc. org/articulo.oa?id=53541312.

23.- Bericht Uber Den XIV. Internationalen Kongress fur Hygiene and Demographie, Vol 1: Berlin, 23-29, September, 1907.

24.- Molyneux E, Riordan F A, Walsh A. Acute bacterial meningitis in children presenting to the Royal Liverpool Children's Hospital, Liverpool, UK and the Queen Elizabeth Central Hospital, Malawi: a world of difference. Ann Trop Paediatr 2006; 26: 29-37. doi: $10.1179 / 146532806$ X90583.

25.- Chacha F, Mshana S E, Mirambo M M, Mushi M F, Kabymera R, Gerwing L, et al. Salmonella Typhi meningitis in a 9-year old boy with urinary schistosomiasis: a case report. BMC Res Notes 2015; 8: 64. doi: 10.1186/ s13104-015-1030-2.

26.- Tsagris V, Vliora C, Mihelarakis I, Syridou G, Pasparakis D, Lebessi E, et al. Salmonella osteomyelitis in previously healthy children: Report of 4 cases and review of the literature.
Pediatr Infect Dis J 2016; 35: 116-7. doi: 10.1097/INF.0000000000000937.

27.- Schutze G E, Schutze S E, Kirby R S. Extraintestinal salmonellosis in a children's hospital. Pediatr Infect Dis J 1997; 16: 482-5.

28.- Boletín Vigilancia de Laboratorio. Salmonella spp. 2012 - 2016. Instituto de Salud Pública de Chile: Departamento de Epidemiología, Ministerio de Salud de Chile. Vol 6. $\mathrm{N}^{\circ}$ 9, Septiembre 2016. Disponible en: http://www.ipsuss.cl/ipsuss/site/ artic/20170329/asocfile/20170329104802/ isp boletinsalmonella 23012017a.pdf.

29.- Price E H, de Louvois J, Workman M R. Antibiotics for Salmonella meningitis in children. J Antimicrob Chemother 2000; 46: 653-5. doi: 10.1093/jac/46.5.653.

30.- Boletín de Brotes 3. Instituto de Salud Pública: Departamento de Epidemiología, Ministerio de Salud de Chile; 2018. http://epi.minsal.cl/ wp-content/uploads/2018/03/Bolet\%C3\%ADn Brotes_3.pdf.

31.- Ambrosius Diener K, Salazar Flores M, Valencia Mayoral P. La salmonelosis en niños: observaciones morfológicas y bacteriológicas en estudios post mortem. Bol Méd Hosp Infant Méx 1986; 43: 300-6. https://pesquisa.bvsalud. org/portal/resource/pt/lil-32569.

32.- Owusu-Ofori A, Scheld W M. Treatment of Salmonella meningitis: two case reports and review of the literature. Int J Infect Dis 2003; 7: 53-60. doi: 10.1016/s1201-9712(03)90043-9.

33.- American Academy of Pediatrics. Salmonella infections. In Kimberly DW, Brady MT,
Jackson MA, Long SS. Red Book 2018 Report of Committee on Infectious Diseases, 31 st ed. Itasca Il. American Academy of Pediatrics; 2018: 711-8.

34.- Peromingo E, Quecuty S, Obando I, Camacho M S, León J A. Recaída de meningitis por Salmonella tras tratamiento con cefotaxima. An Pediatr Barc 2005; 63: 375-6. doi: $10.1157 / 13079824$.

35.- Nau R, Sörgel F, Eiffert H. Penetration of drugs through the blood-cerebrospinal fluid/bloodbrain barrier for treatment of central nervous system infections. Clin Microbiol Rev 2010; 23: 858-83. doi: 10.1128/CMR.00007-10.

36.- Cabrera-Maqueda J M, Fuentes Rumí L, Valero López G, Baidez Guerrero A E, García Molina E, Díaz Pérez J, et al. Antibiotic diffusion to central nervous system. Rev Esp Quimioter 2018; 31: 1-12.

37.- Wu H-M, Huang W-Y, Lee M-L, Yang AD, Chaou K-P, Hsieh L-Y. Clinical features, acute complications, and outcome of Salmonella meningitis in children under one year of age in Taiwan. BMC Infect Dis 2011; 11: 30. doi: 10.1186/1471-2334-11-30.

38.- Chidhara S, Rangasami R, Chandrasekharan A. Magnetic resonance imaging and magnetic resonance spectroscopy in Salmonella meningoencephalitis. J Pediatr Neurosci 2016; 11: 88-90. doi: 10.4103/1817-1745.181253.

39.- Hennedige T, Bindl D S, Bhasin A, Venkatesh S K. Spectrum of imaging findings in Salmonella infections. Am J Roentgenol 2012; 198 : W534-W539. doi: 10.2214/AJR.11.7621. 